\title{
COMMUNICATION IN MASS COOPERATION AS A VUCA FACTOR IN MODERN SOCIO-ECONOMIC SHOCKS
}

\begin{abstract}
Analyzing the prerequisites for the VUCA (Volatility, Uncertainty, Complexity, and Ambiguity) phenomenon - characteristic of the modern world, which is more variable and multilateral than before - the text discusses VUCA with regard to open cooperation in the context of socio-economic interactions.

Instability, uncertainty, complexity, and ambiguity of the world are caused mainly by the expansion of the model of open (mass) cooperation between the participants of public communication. The system of global communication has transformed from a predominantly one-vector model with a targeted audience to an interactive mass system in which not only the specialized subjects of the communication process but also all participants reflect all the components of the VUCA concept. This combination of communicators has characteristics similar to a crowd formed under the influence of external provocation.

The consequences of the impact of VUCA communication factors are spontaneous social and economic upheavals that have emerged with the rapid development of new technologies and communication models (North Africa and the Middle East in 2010-2011, Ukraine in 2013-2014). Over time, this trend has intensified, and the consequences are now manifested on a global scale (as in the case of socio-economic consequences of the 2020 COVID-19 pandemic).

VUCA communication rests on the principles of mass cooperation, thus appropriate approaches and methods should be based on management in the VUCA world.
\end{abstract}

\section{Key words}

VUCA, crisis, mass collaboration, world, Ukraine 


\section{The VUCA phenomenon}

The study analyzes the prerequisites of the emergence of the VUCA (variability, uncertainty, complexity, and ambiguity) phenomenon. VUCA currently characterizes the modern, more variable and undefined world, which is multilateral, complex and ambiguous. The text focuses on VUCA with regard to open collaboration in the context of socio-economic interactions between an unlimited number of participants. For a deeper understanding of the phenomenon, the author will analyze its connection to open collaboration and socio-economic interactions of an unlimited number of participants.

The goal of the article is to show the relationship between the processes of mass communication and the phenomenon of VUCA, and to present the role of mass collaboration as a form of work organization in conditions of uncertainty. To better predict the social and economic upheavals, this and future studies aim at identifying their causes and consequences in the last decade. The results can also be the basis for further analysis and development of an administration model that can be viable in the VUCA world.

\section{Research methodology}

The study uses the descriptive, analytical approach, which mainly relies on source analysis and comparative examination of the research that has addressed social and economic uncertainties as well as related issues and challenges. The paper adopts a qualitative approach with the aim of exploring the phenomenon, which has attracted little attention in the available literature as far as the relationship between mass collaboration and VUCA processes is concerned. This paper and exploratory research can be a stimulus to develop in the future a quantitative research approach. The present study is based on secondary sources including scientific publications, journals, books, periodicals, and reports published within the timeframe of 12 years, from 2008 to 2020 .

The concept of VUCA was first introduced in the US Army College in 1987 to describe the world after the end of the Cold War. The VUCA concept was presented as a means to define strategic leadership in a "changing, uncertain, complex and ambiguous global environment" (Barber, 1992).

The VUCA concept is based on four elements that may have a destabilizing effect on an organization's operations which are based on strategic and tactical 
planning: $\mathrm{V}$ stands for volatility, i.e. the nature and dynamics of change, as well as the nature, factors, and speed of change-causing forces; $U$ means uncertainty, lack of predictability, high probability of unexpected events; $\mathrm{C}$ stands for complexity, associated with the multiplicity of forces, the confusion of issues, the absence of cause-and-effect chains in the environment surrounding the organization; and finally, A means the ambiguity of reality, which increases the likelihood of error, and may lead to confusing causes and effects.

In detail, the manifestations of VUCA components have been analyzed in a number of scientific papers, including Vescio et al. (2004), Purdie-Vaughns and Eibach (2008), Bodenhausen and Peery (2009), and Schick et al. (2017).

The article will consider the factors behind the formation of what is called the "VUCA World" (Bennett et al., 2014). One of them is the transformation of the communication system from a predominantly single-vector model targeted at mass audience to a multiple-vector and interactive one, in which the components of the VUCA concept are reflected not only by specialized subjects of the communication process but also by all participants.

Such a set of communicators has the characteristics of a crowd formed under the influence of external provocation. Such a crowd can be described as a temporary union of a large number of people who are in direct contact with each other and respond to certain stimuli in a very similar way. This distinguishes a crowd from other groupings of people, such as aggregation, audience, group, mass, mob, populace, public, rabble or throng. While a crowd is characterized by a "shared emotional experience, (...) the masses are defined by their interpersonal isolation" (Glynn et al., 2018). Social aspects of crowds consider their formation, management, and ways of controlling them - from the point of view of both individuals and groups. As to crowd control, its goal is often to persuade the crowd to agree with certain views or ideas (such as political or marketing concepts).

In such a system there can be no guaranteed stability, since a large number of active independent communication actors (content generators and opinion publishers) complicates planning and coordination of actions.

Over the past decade, the impact of the VUCA environment on business in general as well as its individual components, such as planning and project management (see e.g. Szpitter \& Sadkowska, 2016) has been extensively explored. The concept of VUCA was researched in the aspect of businesses and markets in publications by such authors as Murali (2015), Saleh and Watson (2017), Kaivooja and Lauraeus (2018), Bartscht (2015), Sharif and Irani (2017), and Johansen and Euchner (2013). 
As summarized by Bennett and Lemoine (2014), the issues associated with the VUCA phenomenon include unstable and unpredictable cost of a resource and/or availability of resources at an unpredictable time and for unpredictable time duration; expected fluctuations in resources, occurring with unknown frequency and amplitude; and lack of relevant knowledge. Other problems are the unclear final outcome of changes even if their causes and direct effects are known; interplay of multiple elements in a system; complex regulatory/policy environment; doubts about the nature of cause and effect; little or no historical information that can be used to predict the outcome; and the complexity of forecasting and planning.

However, George (2017) in his Forbes article describes a new system allowing organizations to meet modern challenges, which he calls VUCA 2.0: Vision, Understanding, Courage, Adaptability. In this approach, vision is the ability of the leader to see through the chaos of mass interactive communication, and to follow the mission, values, and strategy of the organization despite the destabilizing influence of external factors. Understanding is the ability to take advantage of the organization in the changing circumstances of the open-cooperation market. Perseverance means the courage to take on new challenges posed by the chaos of network communication and to make risky and unexpected decisions, while adaptation refers to flexible tactics used to quickly adapt to changing external circumstances without altering the strategic course.

\section{VUCA-globalization}

However, the VUCA phenomenon is noticeable not only in business. It makes an impact wherever there is free (unregulated) and interactive communication between all participants of public relations. Such communication originally developed in the marketing environment through the introduction of CRM tools and their evolution to the user level, employing the technological basis of social networks. On the other hand, social networks considered as a medium of communication also have attracted politicians, representatives of civil society, and others.

A large number of social activity centers are formed on the web, which concentrate not only on sustainable institutions or processes but also on long-term and temporary issues. For example, political parties or political figures, electoral manifestos or individual bloggers have their social media subscribers or followers. However, social network groups tend to form quickly (or at least keep communicating through shared content) around random events such as disasters, 
pandemics, or unpredictable social upheavals. Moreover, such events quickly attract users from already existing groups, who focus on communication in channels that open in response to a more active information stimulus. This feeds more information the thread that has spontaneously emerged. The processes of such type are of high interest for the studies on modern tendencies of mass communication development (e.g. Karpchuk, 2015). In turn, as the new hot topics are of interest to professional journalists, they migrate to the institutionalized media.

Similar processes occur in the field of marketing, where, along with the established manufacturers of products and services, there are amateur circles of producers who can quickly adjust their offer of goods and services.

The spreading of facts and rumors surrounding the 2020 coronavirus pandemic resulted in a considerable concentration of activity of social network users so that for a time the pandemic topped all news services. This not only distracted the audience from other issues such as politics but also stimulated the creativity of content generators (posts, memes) and generated the supply of necessary products and services (for example, spontaneous offers of transport services in the face of public transportation restrictions).

It is the spontaneity of the emergence of powerful information stimuli that causes unpredictable demand. Thus, epidemics and pandemics result in heated public debate, spreading rumors, provoking outbreaks of demand for certain products, including medicines.

The situation surrounding the 2020 pandemic demonstrates all the signs of globalization of the VUCA phenomenon. First, it is the unpredictability and extreme speed of response to the pandemic threat - the almost simultaneous introduction of quarantine measures in most developed countries and the complexity of predicting the consequences in all spheres of public life. Second, it is the multiplicity of significant factors such as economic rivalry between the world's leading economies, energy costs, projections for the consumption of basic raw materials, and more. And third, it is the apparent ambiguity of economic and political realities that leads to destabilization of the financial markets, due to the high probability of errors in the estimated value of assets.

The complexity of forecasting macroeconomic processes manifested itself in the mismatch of both targets and dynamics of the main processes. Thus, if the global financial crisis of 2008 had an economic basis, was projected several years before its peak, and was accompanied by a prolonged slowdown in economic growth for several years, then the situation in 2020 would look different.

According to the International Monetary Fund (IMF), global GDP growth rates weakened to 3.7 percent in 2019 and were expected to decline by no more 
than 3.5 percent in 2020 due to the end of the US-China trade war and solving the Brexit issue. Growth in advanced economies is slower, according to the IMF, which predicted a 2.3 percent growth in this sector of world economy in 2018, 2 percent in 2019 and 1.7 percent in 2020. During the World Economic Forum in Davos in January 2020, IMF published an economic forecast stating that the world had managed to avoid significant economic shocks that would have led to a global recession (World Economic Outlook, January 2020).

Instead, as noted in the OECD interim economic assessment report (OECD, 2020), the impact of the Covid-19 outbreak on the economic outlook is strong. While growth has been weak but steady so far - following a pandemic outbreak due to restrictions on the movement of people, goods and services, and containment measures such as production closure - the production and domestic demand in China and around the world have sharply declined. The projected growth of the world economy in 2020 has already decreased by more than 0.5 percent by the beginning of March, and the projected Chinese economy growth decreased by almost 1 percent (however, this forecast was prepared before the introduction of large-scale anti-epidemic measures in Europe and the US).

Compared to the previous economic crisis of 2008, no one anticipated such a large reduction in the world economy. The 2008 crisis was generally predicted several years before it began - following the unfolding of the US mortgage default crisis in 2006 as a consequence of unrestricted demand for cheap loans due to the obvious errors in the regulation of financial markets (Weissman, 2009). The resale market showed noticeable signs of overheating well before the crisis began. Thus the 2008 crisis was not unexpected, yet it swept over the world due to globalization of both financial instruments and approaches (such as the takeover of mortgage and consumer lending).

Considering the impact the H1N1 swine flu pandemic (which broke out in the spring of 2008 and lasted for more than a year) - had on the society and the economy, as, it is difficult to determine its significant impact on trends in macroeconomic outcomes that have been projected to decline before. Even in 2009, the economy started a rapid recovery. Moreover, the H1N1 pandemic was quite large - from 0.7 to 1.4 million people became infected (Kelly et al., 2011).

However, at the time of the financial and epidemic turmoil of 2008-2009, the world was much more predictable and less volatile than in 2020. Probably the reason is the significant increase of the importance of free mass communication, which is closely linked to the ability of its participants to significantly influence the course of socio-economic processes by the content generated mostly in global social networks. 
In the decade or so since the end of the last global financial crisis, the number of Internet users and social networks has increased, which has been accompanied by the development of various forms of open interaction and mass cooperation. Today, at the level of World Economic Forum everyone admits that on a global scale, there is a high level of volatility, uncertainty, complexity and ambiguity, which has a direct impact on all areas of business (Kayvan, 2020).

\section{Socio-political upheavals}

VUCA factors tend to appear where communication processes are lost or new communication channels are emerging and evolving to reach the vast majority of audiences. It has been shown that these factors had become central to the outbreak of social upheavals that began in North Africa and the Middle East along the turn of 2011, known as the Arab Spring (Fedoniuk \& Strilka, 2014).

The countries of the region that had been relatively prosperous (socially and economically) suddenly exploded with uprisings that led to changes in power or even to armed conflicts. Countries that started revolutions were characterized by a relatively low level of corruption - Egypt ranked $98^{\text {th }}$ in the world, Tunisia ranked 59 (higher than Italy, Romania, and Greece), according to the Corruption Perceptions Index (CPI, n.d.), and the level of crruption had been declining steadily. They also demonstrated relatively high rates of life satisfaction as compared to e.g. Estonia, Latvia or Romania. In terms of economic development, the region was characterized not only by relatively high values of the main economic indicators but also by the level of real income of the population - the percentage of people who at the time of the revolutions were living on less than $\$ 1$ a day was no more than 3-20\% (Population below poverty line, n.d.).

One can argue that - compared to most other countries in the world - Tunisia, Egypt, Libya and other countries in North Africa and the Middle East did not have any special prerequisites to start large-scale social movements and upheavals. The main driver of the revolutions was the spontaneous consolidation of the public within the global social networks, most notably Facebook and Twitter, with the widespread use of the power of mobile broadband visualization tools (YouTube). Already in 2010 the share of the Facebook social network population in Tunisia was $15.8 \%$ (more than in Germany and Poland), 5.1\% in Egypt, 2.8\% in Libya ("Facebook Penetration Rate", n.d.), and the share of regular Internet users in these countries ranged from 10 to $30 \%$ (calculated according to ITU Databases, n.d.). 
The basis of the revolutions in the North Africa and the Middle East region was the rapid informatization, increase in access to telephones among the population and, most importantly, mobile access to the Internet, used as a space for free exchange of information in the context of considerable restriction of civil and political freedoms. What gave the impetus for public movements was the open communication among citizens connected by social networks. This was the first time social media provided a platform for rapid unification of interested participants around a common goal, specification of the said goals and coordination of actions. For local authorities, who had traditionally controlled the media sphere represented by traditional media, this became a VUCA factor for which they were unprepared. Interestingly, the likelihood of destabilization in the region due to the rapid development of information communication was predicted in a RAND report as early as 2003 (Burkhart \& Older, 2003).

Equally rapid and unexpected for the authorities, the emergence of alternative channels of mass communication had become the basis for the deployment of the processes that led to a change of government in Ukraine in 2014 (Fedoniuk, 2018). Only a few years before the revolution, Ukraine had a rapid growth in the number of Internet and social network users. In 2008, the percentage of citizens with computers was $26 \%$ and in 2013 - 54\% (more than a two-fold increase in 5 years). At the beginning of the Euromaidan, more than $50 \%$ of Ukrainians aged 16 years and older used the Internet, which is three times as many as in 2008. The share of the population using social networks also grew very fast: in 2010 it was $35 \%$, and in the first half of $2013-63 \%$ of the total number of active Internet users (Vyshlynskiy, 2013).

Both for Ukraine and the Arab Spring countries it was not the number of Internet and social network users that became a defining factor, but the dynamics of their growth. Along with the increase in the number of users of social networks, their activity in the Internet also grew significantly during the confrontation in Independence Square in Kyiv. Due to that new social media audience, there has been a dramatic increase in the number of news inquiries that have been answered through online referrals to news sites, mainly those not controlled by the authorities.

Another factor in the volatility of the revolutionary situation was the then technological novelty - online television with independent streaming channels. Broadcasts streamed live by individuals from the hot spots gained great popularity.

The instability and unpredictability of international systems are also manifested in the unexpected unfolding of armed conflicts. This happened in Ukraine 
in 2014, and resulted in a significant public response, as it did not correspond to the established notions of the balance of power and the state of international security in the region (analyzed by Bodziany \& Kocori, 2018).

In the VUCA world, novelty and speed of process deployment are crucial. They can stem from latest technological solutions but also from natural disasters, epidemics or other unexpected events that cause an avalanche of information capture among the vast majority of the audience.

The main problem that causes difficulties in managing processes in the micro- and macro-environment of the VUCA world is the fundamental inadequacy of the traditional model of administration, which is based on isolation and limitation of an institution together with its resources. It is a dominant model, described by Coase in 1937, but it ceases to operate under VUCA conditions. VUCA communication involves expansion or even blurring of the boundaries of a traditional enterprise or institution, which is increasingly using external knowledge and resources instead of relying on internal, closed and hierarchical models. Open network corporations are emerging, and they partner with experts and clients worldwide through global communications channels. The Internet is being transformed from a means of presenting information into a new generation of information space, one with unlimited intellectual capacity and capable of meeting the needs of both consumers and product providers.

Thus there is no point in dealing with uncertainty and volatility or trying to minimize the impact of multiple factors. Since VUCA is the result of a large number of amateur communicators, it is necessary to use their communication potential to find and attract resources - and this is exactly what open (mass) cooperation is about.

Mass collaboration is a form of collective cooperation that occurs when a large number of participants work independently on a joint project, often of a modular nature (Cress, 2016). The concept of mass cooperation was formulated by Tapscott and Williams (2008) and it has been developed in relation to various spheres, such as management in the VUCA world (Borjigen, 2015; Krawchuk, 2017).

An example of mobilization of resources from the network in the form of open cooperation during the Ukrainian Revolution were the mentioned live streams. The broadcasters often used the streaming services of an independent US project Ustream (which is essentially a social network), which made it possible to quickly organize the broadcast and ensure that a large audience would have access to the channel. Ukrainian Internet TV projects that were actively involved in broadcasting protests - such as Hromadske.tv, Grom TV, Spilno.tv 
and UkrStream.tv - made 24/7 live broadcasts from the sites of all current events through the Ustream service. A feature of this technology is its accessibility for an average event witness - after registering with Wi-Fi or a mobile network and logging in, the user can stream live videos from an external webcam or a camera in their smartphone, tablet or laptop. The stream is saved as a video that can be watched later.

It was enough for the operators of the streaming video site to allow public journalists to distribute their videos in real time without restrictions on the number of views, advertisements, free promotion, and technical support. The availability of such a platform helped a number of media projects to achieve success, such as the non-profit UkrStream.tv, which had amassed over 40 million views by the end of Maidan. During the Revolution, the channel covered only the rental of cameras and filming venues, mostly through voluntary open accounts (Fedoniuk, 2018).

It is worth noting that in the period preceding the Maidan, public organizations undertook a number of activities using Ustream services; this made people aware of the technology and helped Internet users acquire experience with it, which proved useful during broadcasting the events of the revolution.

Other examples of successful open co-operation in Ukraine include volunteer battalions and volunteer projects initiated on the web to support the Ukrainian military in combating external aggression in eastern Ukraine.

\section{Conclusions}

The concept of VUCA (more variable, uncertain, complex and ambiguous or multilateral world), which was originally developed for the business environment, today also characterizes socio-economic and political relations at various levels, including the global one.

A system where VUCA factors are at play can guarantee neither the stability of its nature and dynamics of change nor the origin, factors, and speed of change since planning and coordination of actions are impossible with a large number of active independent communication actors (content generators and opinion publishers). Accordingly, it results in uncertainty in the system, lack of predictability, and high probability of unexpected events. The complexity of such a system is related to a multiplicity of forces, confusion of issues, absence of cause and effect aspects in the environment of the "communicating crowd" that surrounds the organization. Additionally, the ambiguity of reality increases the likelihood of error, resulting in the confusion of cause and effect. 
This was reflected particularly in the specifics of the unpredictable sociopolitical upheavals that took place in North Africa and the Middle East as well as Ukraine. The VUCA phenomenon may also be likely to cause significant adverse economic consequences of unforeseen cataclysms and epidemics (such as the 2020 coronavirus pandemic). The main reason for the increase in VUCA factors is the transformation of the mass communications sphere from a model with a limited number of communicators to a model with an unlimited number of interactive communicators that operate mainly using social networks.

A possible solution to the problem of the functioning of institutions and to managing projects and processes in the VUCA world is to use the model of open (mass) collaboration. and integrated solutions, including finished products and services. The advantage of this approach is the ability to use a virtually unlimited resource - the potential of network members.

It is likely that in the near future new approaches to planning, forecasting and administering at the level of international systems based on the use of open collaboration potential will have to be applied due to the increased influence of VUCA factors. Hence there are reasons to define the connection between the VUCA processes and the development of mass communication in the form of mass cooperation. This connection is likely due to strong social and economic shocks occurring on a regional and global scale, and may therefore offer ample subject matter for further research.

\section{REFERENCES}

Barber, H. F. (1992). Developing Strategic Leadership: The US Army War College Experience. Journal of Management Development, 11(6), 4-12.

Bartscht, J. (2015). Why systems must explore the unknown to survive in VUCA environments. Kybernetes, 44(2), 253-270.

Bennett, N., \& Lemoine, G. J. (2014). What a Difference a Word Makes: Understanding Threats to Performance in a VUCA World. Business Horizons, 57(3), 311-317.

Bodenhausen, G. V., \& Peery, D. (2009). Social Categorization and Stereotyping in Vivo: The VUCA Challenge. Social and Personality Psychology Compass, 3(2), 133-151.

Bodziany, M., \& Kocori, P. (2018). Ivan at the Gates! - Armed Conflict in Ukraine and the Moral Panic in Poland? Trames-journal of The Humanities and Social Sciences, 22, 137.

Borjigen, C. (2015). Mass collaborative knowledge management: Towards the next generation of knowledge management studies. Program: electronic library and information systems, 49(3), 325-342. 
Burkhart, G. E., \& Susan Older, S. (2003). The information revolution in the Middle East and North Africa. Santa Monica, CA: RAND Corporation. Retrieved from https:// www.rand.org/pubs/monograph_reports/MR1653.html

Coase, R. (1937). The Nature of the Firm. Economica, 4(16), 386-405.

CPI. (n.d.). Corruption Perceptions Index website. Retrieved from https://www.transparency.org/en/cpi\#

Cress, U., Moskaliuk, J., \& Jeong, H. (Eds.). (2016). Mass Collaboration and Education. n.p.: Springer, Cham. DOI: https://doi.org/10.1007/978-3-319-13536-6

Facebook Penetration Rate Data for All Countries. (n.d.). Retrieved from https: http:// www.economywatch.com/economic-statistics/economic-indicators/Facebook Penetration_Rate/

Fedoniuk, S. (2018). Mass Collaboration as a Factor of the Ukrainian Revolution 20132014. Language - Culture - Politics: International Journal, 1, 209-218.

Fedoniuk, S., \& Strilka, O. (2014). Masove spivrobitnitstvo yak tschinnik revolyutsyi "Arabskoy vesny". Naukovyi visnik Skhidnoevropeiskovo natsional'novo universitetu imeni Lesi Ukrainki. Seriya: Mizhnarodni vidnosini, 14(291), 120-123.

George, B. (2017, 17 Feb). VUCA 2.0: A Strategy for Steady Leadership in an Unsteady World. Forbes. Retrieved from https: https://www.forbes.com/sites/hbsworkingknowledge/2017/02/17/vuca-2-0-a-strategy-for-steady-leadership-in-an-unsteadyworld/\#3beb5dff13d8

Glynn, C., Herbst, S., Lindeman, M., O’Keefe, G. J., \& Shapiro, R. Y. (2018). Public opinion (3rd ed., e-book). New York: Routledge. DOI: https://doi.org/10.4324/9780429493256

ITU Databases. (n.d.). Retrieved from https: http://www.itu.int/ITU-D/ICTEYE/Reporting/DynamicReportWizard.aspx

Johansen, B., \& Euchner, J. (2013). Navigating the VUCA World. Research-Technology Management, 56(1), 10-15.

Kaivo-oja, J. R. L., \& Lauraeus, I. T. (2018). The VUCA approach as a solution concept to corporate foresight challenges and global technological disruption. Foresight, 20(1), 27-49.

Karpchuk, N. (2015). Communication Policy as the Source of Citizen's Trust. The Copernicus Journal of Political Studies, 1(7), 64-80. DOI: http://dx.doi.org/10.12775/ cjps.2015.01.05

Kian, K. (2020, 5 Mar). 6 ways to thrive in an out-of-control world. World Economic Forum. Retrieved from https://www.weforum.org/agenda/2020/03/6-ways-to-thrivein-an-out-of-control-world/

Kelly, H., Peck, H. A., Laurie, K. L., Wu, P., Nishiura, H., \& Cowling, B. J. (2011, 5 Aug). The Age-Specific Cumulative Incidence of Infection with Pandemic Influenza H1N1 2009 Was Similar in Various Countries Prior to Vaccination. PLOS ONE. Retrieved from https://journals.plos.org/plosone/article?id=10.1371/journal.pone.0021828

Krawchuk, F. T. (2017). Collaboration in a VUCA Environment. In R. Elkington, M. V. D. Steege, J. Glick-Smith, \& J. M. Breen (Eds.), Visionary Leadership in a Turbulent World (pp. 133-154). Bingley: Emerald Publishing Limited. 
Murali, A. (2015). The VUCA Company. Journal of Family Business Management, 5(2), $317-318$.

OECD. (2020, 2 Mar). OECD Interim Economic Assessment Coronavirus: The world economy at risk. Retrieved from https: http://www.oecd.org/economic-outlook/

Population below poverty line: Countries Compared. (n.d.). NationMaster. Retrieved from https://www.nationmaster.com/country-info/stats/Economy/Population-belowpoverty-line

Purdie-Vaughns, V., \& Eibach, R. P. (2008). Intersectional Invisibility: The Distinctive Advantages and Disadvantages of Multiple Subordinate-Group Identities. Sex Roles, 59(5-6), 377-391.

Saleh, A., \& Watson, R. (2017). Business excellence in a volatile, uncertain, complex and ambiguous environment (BEVUCA). The TQM Journal, 29(5), 705-724.

Schick, A., Hobson, P. R., \& Ibisch, P. L. (2017). Conservation and sustainable development in a VUCA world: the need for a systemic and ecosystem-based approach. Ecosystem Health and Sustainability, 3(4). Retrieved from https: https://esajournals. onlinelibrary.wiley.com/doi/pdf/10.1002/ehs2.1267

Sharif, A. M., \& Irani, Z. (2017). Policy making for global food security in a volatile, uncertain, complex and ambiguous (VUCA) world. Transforming Government: People, Process and Policy, 11(4), 523-534.

Szpitter, A., \& Sadkowska, J. (2016). Using VUCA matrix for the assessment of project environment risk. Zarzadzanie i Finanse, 14(2), 401-413.

Tapscott, D., \& Williams, A. D. (2008). Wikinomics: How Mass Collaboration Changes Everything. New York: Portfolio.

Vescio, T. K, Judd, C. M., \& Kwan, V. S. Y. (2004). The crossed-categorization hypothesis: Evidence of reductions in the strength of categorization, but not intergroup bias. Journal of Experimental Social Psychology, 40(4), 478-496.

Vyshlynskiy, G. (2013). Auditoriya Interneta v Ukrainie: dinamika, mobilnyi Internet, starye i novye pol'zovateli: issledovaniye GfK Ukraina. Retrieved from http://www. gfk.ua/public_relations/presentations/index.ua.html

WEF. (2015). Outlook on the Global Agenda 2015 - World Economic Forum. Retrieved from https://reports.weforum.org/outlook-global-agenda.../the-call-to-lead/

Weissman, R. (2009,12 Nov). Reflections on Glass-Steagall and Maniacal Deregulation. Common Dreams. Retrieved from https: https://www.commondreams.org/ views/2009/11/12/reflections-glass-steagall-and-maniacal-deregulation

World Economic Outlook. (2020, Jan). Tentative Stabilization, Sluggish Recovery? Retrieved from https://www.imf.org/en/Publications/WEO/Issues/2020/01/20/weoupdate-january2020 